\title{
Erratum to: Development of a Framework to Characterise the Openness of Mathematical Tasks
}

\author{
Joseph B. W. Yeo ${ }^{1}$
}

Published online: 17 May 2016

(C) Ministry of Science and Technology, Taiwan 2016

\section{Erratum to: Int $\mathbf{J}$ of Sci and Math Educ \\ DOI 10.1007/s10763-015-9675-9}

The article was updated. In the first paragraph of the section 'Mathematical Problem, Investigation and Real-Life Task', the quotation by Henderson \& Pingry was corrected.

The online version of the original article can be found at http://dx.doi.org/10.1007/s10763-015-9675-9.

\section{Joseph B. W. Yeo}

josephbw.yeo@nie.edu.sg

1 National Institute of Education, Nanyang Technological University, Singapore, Singapore 